\title{
HAVE WE REACHED PEAK DESIGN THINKING? Are we entering a new paradigm for how it is used within practice and business?
}

\author{
DOUGLAS Michelle; KIERNAN Louise ${ }^{b}$ SPRUCE Johnc and RYAN Annmarie ${ }^{b *}$ \\ a Griffith University, Australia \\ b University Limerick, Ireland \\ c Liverpool John Moores University, UK \\ * Corresponding author e-mail: Michelle.douglas@griffith.edu.au \\ doi:10.21606/dma.2018.727
}

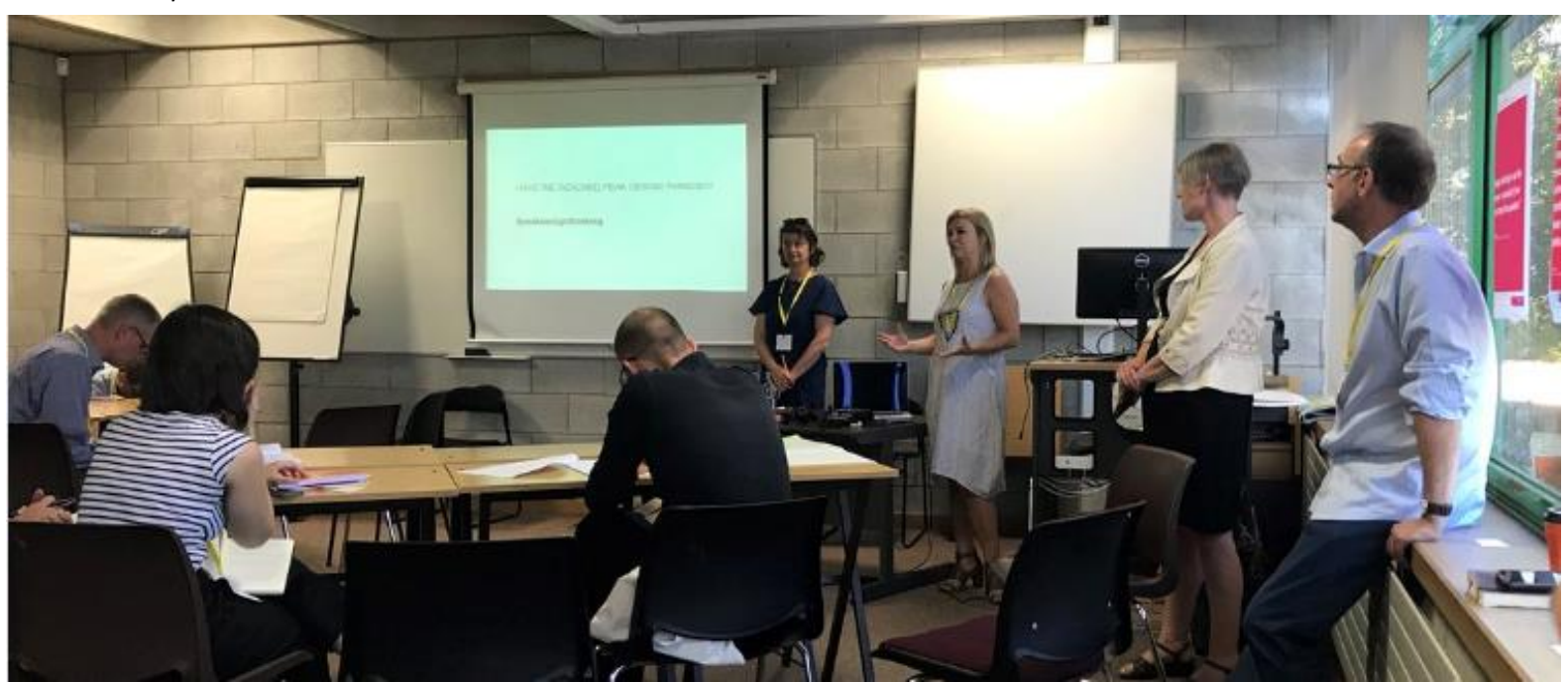

Figure 1 Have we reached peak design thinking?

Design thinking has gained recognition as an acclaimed process for generating innovative, human-centred solutions at a social and business level. It has also gained notoriety amongst many designers, who claim that its success as an exported element of the design process has resulted in its commodification, and led to it becoming a diluted series of processes that lack criticality. As design disciplines and the role of designers continue to evolve, we should reflect on design thinking's original context and understand its progression into a non-design world. Our hypothesis is that design thinking has reached a 'peak' in contemporary practice, and as the term 'design' is further adapted and conformed to suit a business function, this Conversation will elicit a constructive debate on the future of design thinking and its positioning within design and non-design industries. Has design thinking's commodification and consumption as a step-by-step road map to innovation reduced it to a mainstream approach? Can we use the undoubted successes of design thinking as a catalyst for future design research? It is anticipated that through 
analysis and discussion, this Conversation will inform the conceptualisation of enhanced methodological frameworks that aim to support innovation across divergent industry practices.

keywords; Design thinking; design practice; design skills; non-design disciplines

\section{Introduction}

\subsection{Have we reached peak design thinking?}

The aim of the Conversation was to promote dialogue and elicit experiences from the audience, enabling the identification of varying approaches in the application of design thinking. For example, are there discernible disconnects between design thinking as employed by non-designers, and the design process, as practiced by designers? The Conversation may reveal high levels of plurality in the application of design thinking amongst these different groups, and identify common elements in determining degrees of success or failure. To guide the session the following sub questions were used:

1. Should there be a designer involved in all design thinking processes or is everyone a designer?

2. What is the difference (or is there a difference) between design and design thinking?

3. When does design thinking not work?

\section{The DRS2018 Conversation session}

In advance of the session the Conversation was sparked via a Twitter feed using \#peakdesignthinking to elicit people's thoughts on the topic. The Conversation session was convened as follows:

\subsubsection{Section 1: background. $10 \mathrm{~min}$}

The participants were introduced to the format of the session and invited to respond via Twitter throughout the session. The background to the topic was provided.

\subsubsection{Section 2: choose your position. $10 \mathrm{~min}$}

The participants were asked to put their initial thoughts about design thinking on post-it notes and apply them to the wall at the beginning of the session. A number of posters with positional statements were also in place around the room. Delegates were then asked to place a sticker on the poster with the statement they identified most with. This participatory exercise enabled the conveners to better curate the discussion based on who was in the room.

\subsubsection{Section 3: Discussion. 1 hour}

As listed above three sub questions were posted between the conveners and delegates to discuss and debate the theme. For each of the three questions delegates were asked to:

- Give an individual response on post-it notes,

- Discuss as a group.

- Summarise group discussion further on post-its.

- Finally, pick one person from each group to summarise to rest of room. 


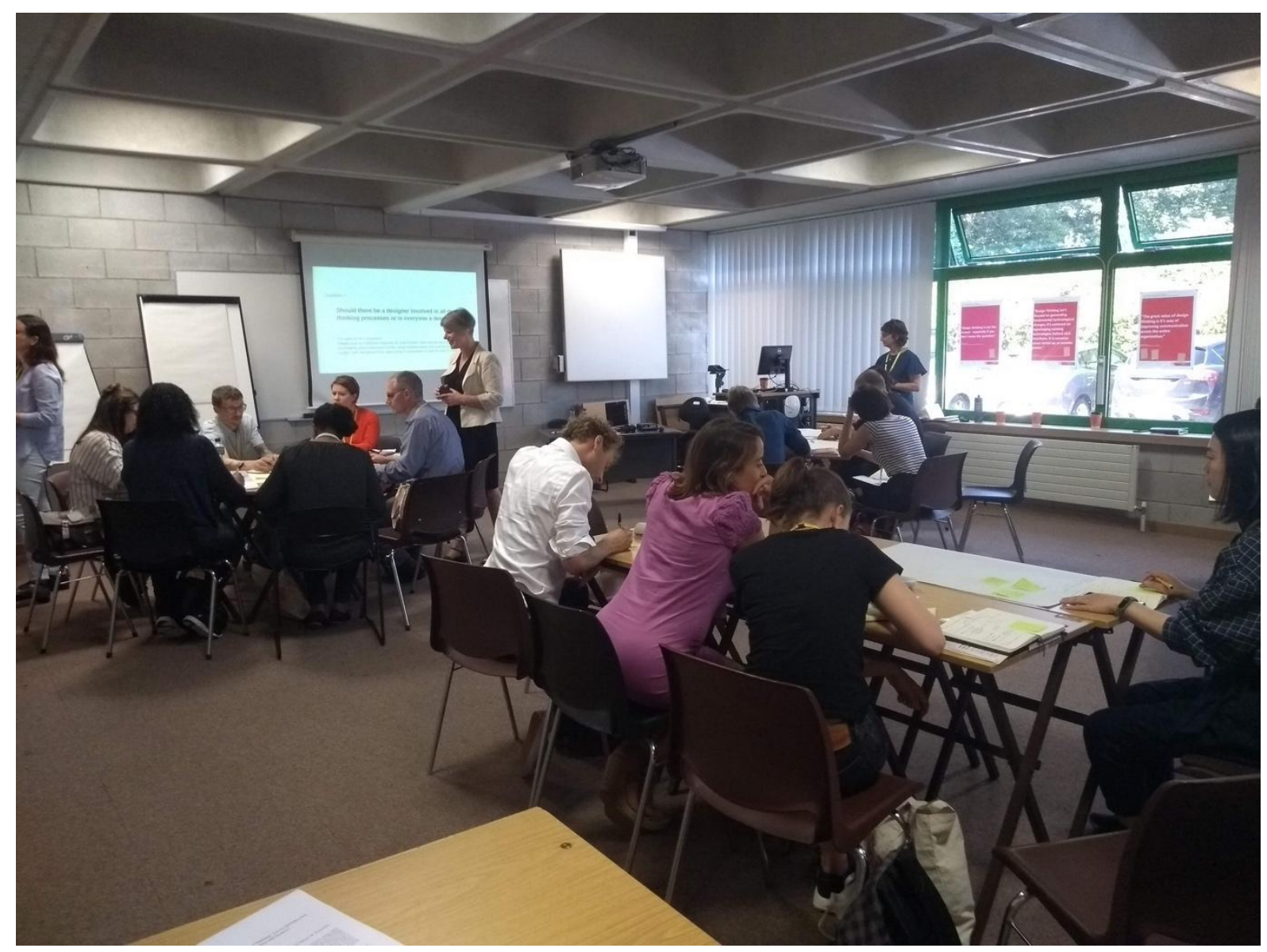

Figure 2 Peak design thinking Conversation in action

\subsubsection{Section 4: The path forward. $30 \mathrm{~min}$ :}

An open discussion took place where solutions were proposed and discussed as to how we can use the success of design thinking as a catalyst for producing more and effective methodologies that can be applied by other disciplines.

\section{The DRS2018 Conversation findings}

\subsection{Choose your position}

A number of the session's participants used \#peakdesignthinking to post initial comments at the start of the Conversation, aligning to their starting viewpoint, and then throughout the session as the sub questions were discussed, with retweets and comments reaching beyond the immediate Conversation participants. The Twitter hashtag recorded 126 engagements on the topic during and after the Conversation. The majority of the Twitter comments reflected the views and discussions that emerged through the Conversation, such as that "everyone can be a designer - it doesn't mean everyone is good at it" and that "often the context of commissioning design can limit the capacity to imagine better futures" and also raising views that ask "does it matter how we define and package design thinking or rather look on the impact of design thinking" as a priority. The range of comments highlight some of the polarities of opinion surrounding design thinking framed within the Conversation proposal itself, and provided a useful 'sub-layer' of commentary to the live Conversation. 


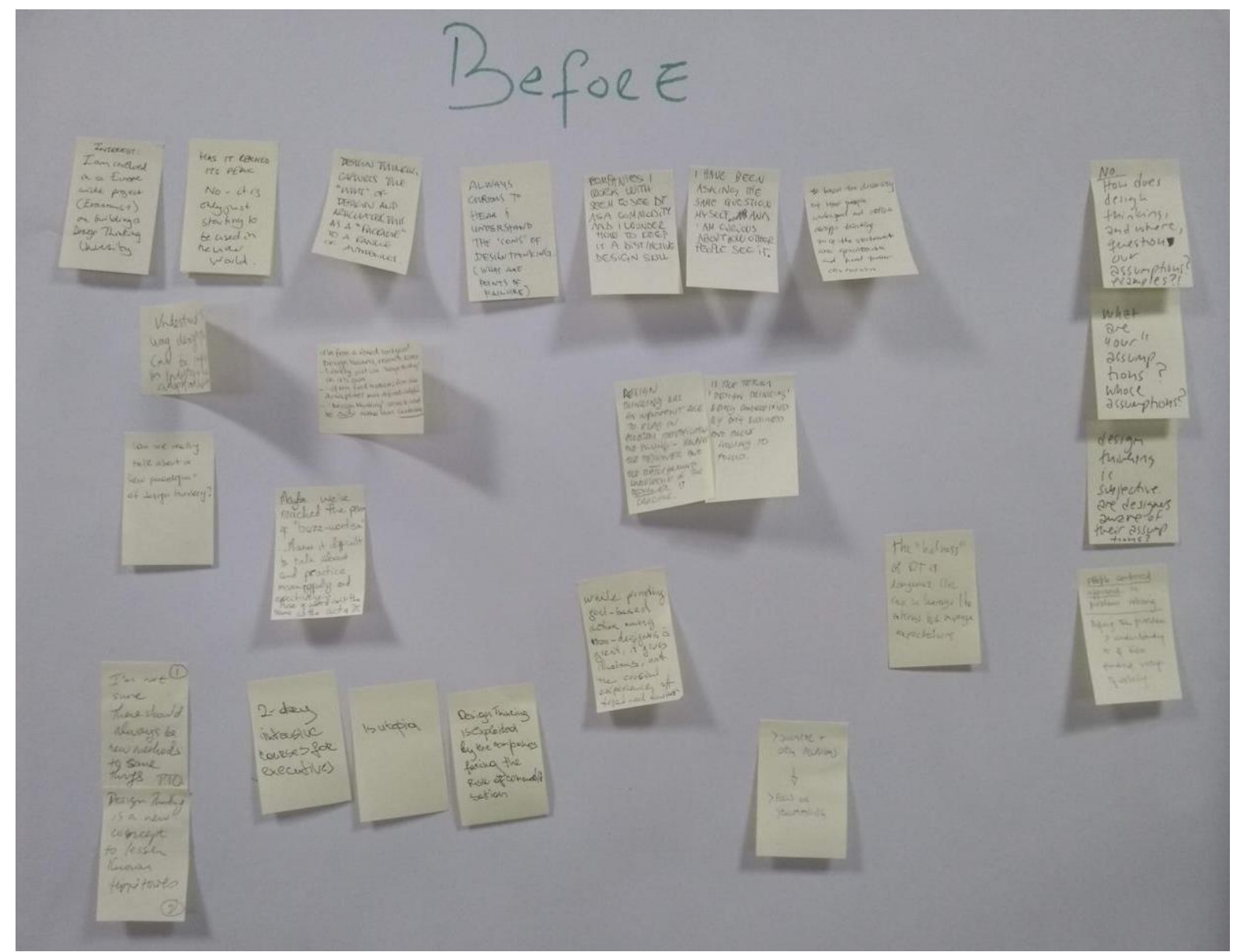

Figure 3 Initial thoughts from participants at beginning of session

A number of posters that highlight the existing polarity of opinions surrounding design thinking were positioned around the conversation venue itself, to act as prompts and help draw out audience opinion. The posters contained statements from design industry commentators, practitioners, academics and prominent design blog writers. Delegates were then asked to place a sticker on the poster with the statement they identified most with. The highest 'scoring' statements amongst the conversation participants were less reflective of the polarizing opinion that design thinking generates. Seven participants aligned mostly to Gadi Amit's 2018 comment that "A six week course at Stanford won't make you a designer." http://fortune.com/2018/03/07/what-is-design-thinking/. The other most identified statement being "Design thinking is more about a mindset that focuses on how to look at challenges around us. Methodologies \& processes are important, but these are mere tools." From Amol R. Kadam (2018) https://www.entrepreneur.com/article/310282 also recorded seven post-its. These two statements are perhaps more measured and descriptive of the potential value a design thinking methodology may offer within the design process. 


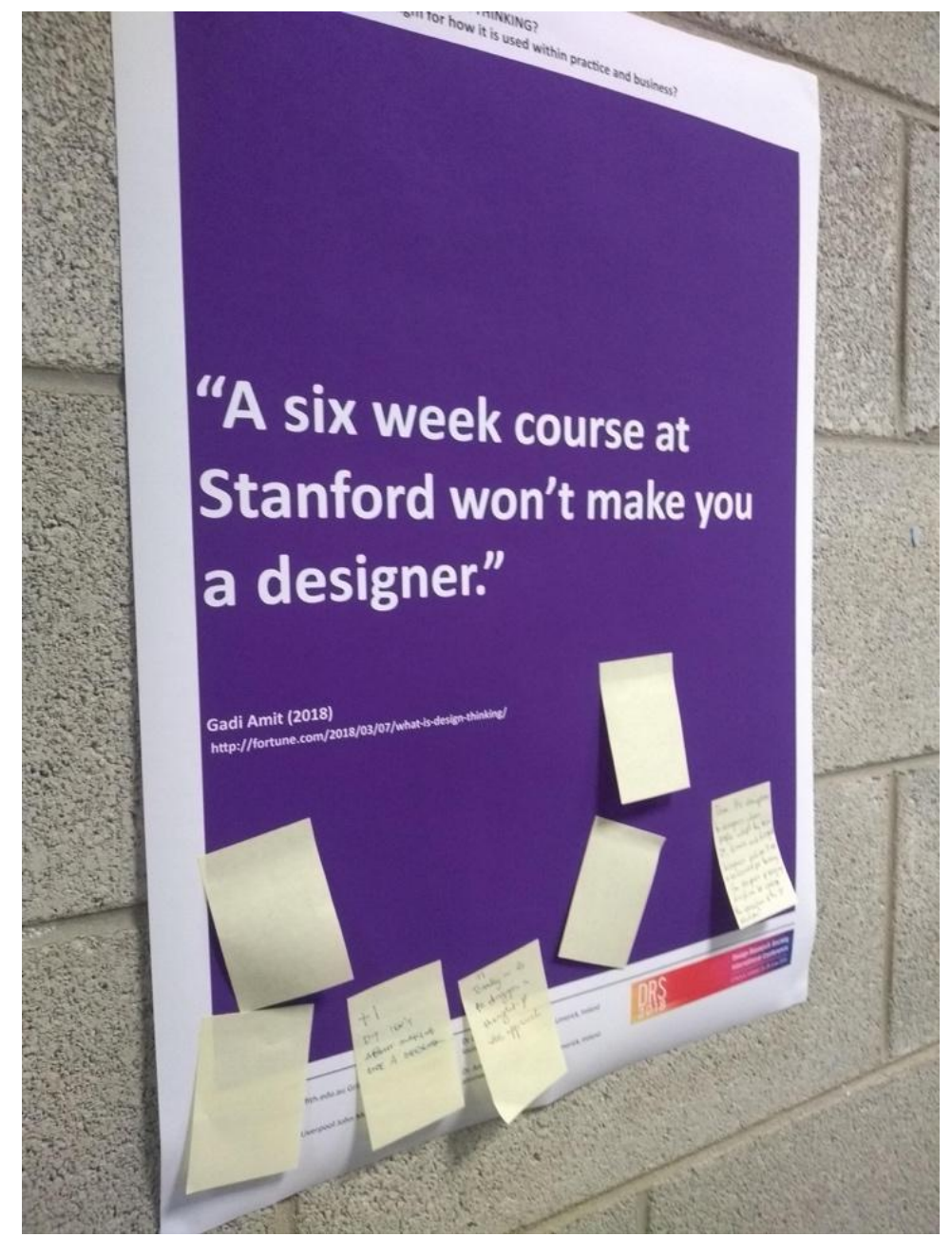

Figure 4 High-scoring participant poster statements

The selections may be reflective of the Conversation audience, mainly comprising design researchers and academics rather than design practitioners. Participants' selections of other statements were very evenly spread across positive and negative viewpoints. Such as Natasha Jen's 2018 statement that "design thinking packages a designer's way of working for a non-design audience by way of codifying design's processes into a prescriptive, step-by-step approach to creative problem solving - claiming that it can be applied by anyone to any problem." https://uxplanet.org/design-thinkingis-not-doomed-its-misused-cda1cf8948e1 versus Gadi Amit's 2018 statement that "The great value of design thinking is it's way of improving communication across the entire organization." http://fortune.com/2018/03/07/what-is-design-thinking/. See poster examples below. 


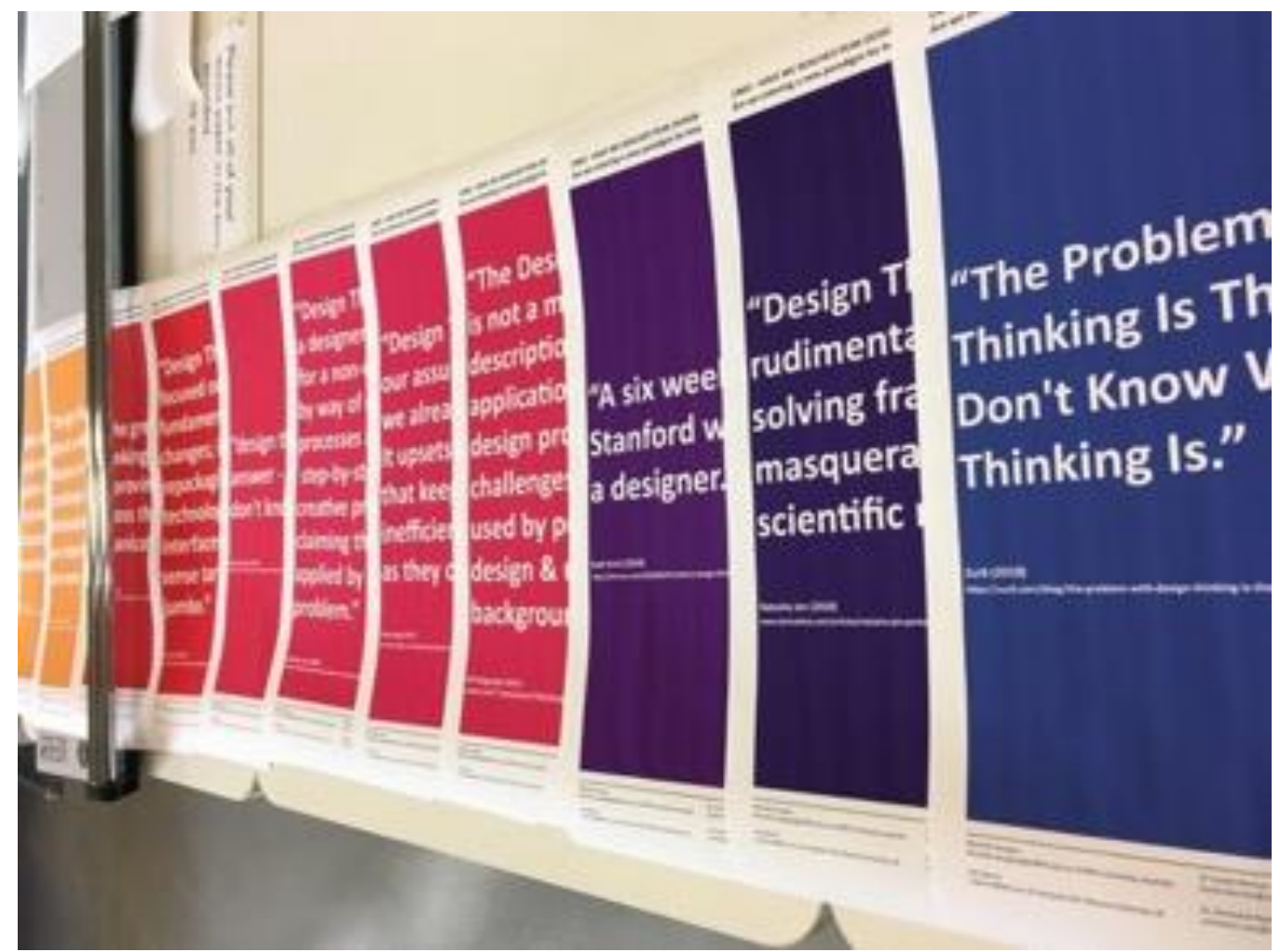

Figure 5 Sample Statement Posters used for the Conversation

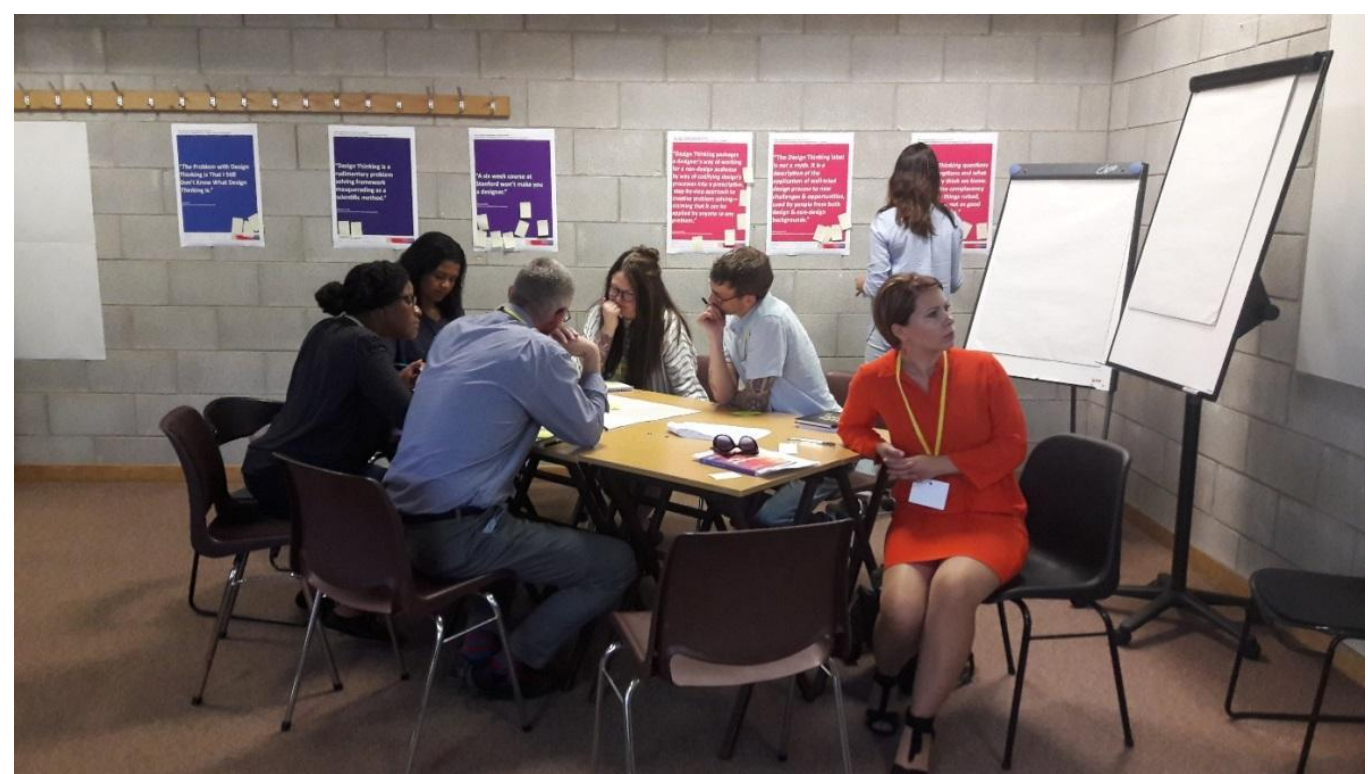

Figure 6 Placing stickers on the posters

\subsection{The Conversation}

In order to facilitate further discussion following the "choosing your position" introductory phase, participants were propositioned with three main questions that investigated the designer's role in design thinking, the differences between design-doing and design-thinking and the functionality of design thinking. 


\subsubsection{Q1: Should there be a designer involved in all design thinking processes or is everyone a designer?}

This is a question which had some opposing views with some people believing that the designer is essential to the process.

Everyone is not a designer. It depends on your educational experience, your practical experience, the craft of being a designer. We strongly believe that a 4-week course in design thinking doesn't make you a designer.

We're saying that you do need a designer in the process, but it depends in what stage of the process. If it's the very start of the process where you're trying to identify the problem, do you need a designer to facilitate that? Someone else can facilitate that. But they (designer) would be there to witness what's being said or to capture it.

Everyone is not a designer. Sometimes it may be helpful to have a designer involved.

Others believed that it was not always necessary to have a designer on the project.

The non-designer may find loop holes that designer [sic] is unaware of and will help facilitate solving the problem.

The context and scale of the project was considered to be a factor.

In small organisations without a designer it is OK. On the other hand large projects should not spare on a designer.

There was also a view that the term 'design thinking' assumed that a designer was not involved and that it was a toolkit for non-designers.

Is design thinking not a way to 'tell' how design tools are to be used by non-designers?"

The term 'designer' was also considered to be vast making it difficult to define the role and the skills that a designer could bring to the project.

I think that for example a visual communication designer's role is inferior to an industrial designer's role.

You can't categorise a designer as a designer or a design thinker, I think it's a very vast area, but the background (as a designer) has an influence on how we see the world.... I look at the detail in the world and I don't think a lot of businesses look at details. I worked in corporations where they don't see the small things, like I do. So I think they don't see the problems sometimes.

It was also pointed out that designers were not all the same in terms of thinking.

Everyone does not think alike and even designers think subjectively.

It depends on the nature of the project and the designer's knowledge.

What was considered as being important was that the process had someone who could coach, lead and mentor the project with an understanding of design.

Not every squad requires a formally trained designer. However each squad does require a coach to help them advance practice. 
Leadership, mentorship, coaching and facilitation is required (trained as a designer or otherwise).

Perhaps it's more necessary to have a person with some design understanding and a design mind-set involved.

\subsubsection{Q2 What is the difference (or is there a difference) between design and design thinking?}

There was a sense that the boundaries were very much blurred but that design requires experience and skills learnt over time. Designers were seen to be good at exploration and experimentation while design thinking was seen as a process or toolkit that can be followed by any reasonably creative person.

Blurry boundaries, however design is a discipline and 'design thinking' (as posted by IDEO and spread by others) are processes and design tools to be 'spread' and 'sold' in non-design contexts.

Any creative individual can have the ability of design thinking. Design requires experience, knowledge and an education in a design field.

There is a difference. Good designers do it intuitively. They may not even be able to articulate it or identify a process or tools but they practice it daily. Design thinking tries to put tools and a process to help others tap into what designers practice in different forms in varying disciplines.

We were talking about design being more than just craftsmanship. It's not craftsmanship alone. There seems to be some intuitive problem solving component, so intuitive problem solving plus craft. And then you get design. But not all of us were in agreement.

There was also a sense that design thinking was a co-creative sense making process involving and embracing people early on in the process while design was traditional and more craft and solutionoriented requiring both aesthetics and technical skill.

Design - traditional. Has a focus on strange making and demands a small amount of sense making. Design thinking places an emphasis on sense making and is wholly cocreative.

Design: intent behind an outcome. Creating a better future, craft. Design thinking: an approach/framework for diverse teams to embrace people ambiguity and iteration.

Design thinking is a co-creative strategic activity with an emphasis on sense making practiced at the early stage of the innovation process.

Design thinking $=$ process. Design $=$ result. Design thinking leads to design.

Working in industry, I think when people hire a designer, in most cases, in $90 \%$ of the cases they're not thinking about design thinking, they're thinking about the craft...they want someone to make a website look good, they might be thinking about the UX process, but I think $90 \%$ of the time, the hirer of the designer doesn't think about design thinking when they're hiring a designer... which I think causes some problems with the definition and tasks that should be undertaken by the designer. 
Design was seen to be focused on artefacts while design thinking worked on organisations and systems.

Simple distinction of John Maeda: " 'Classical' design cares about artefacts (real or virtual), design thinking works on organisations.

While differences were verbalised by the participants there was a belief that there was an overlap between the two.

Both design and design thinking are ways to problem solve.

Design is thinking visualised in an object or physical something. So thinking is part of design process and therefore the designer is a thinker.

When debating the how design thinking should be used in companies, there was some debate on the correct use of context and role of the designer.

Graphic Design education is sometimes is [sic] just producing the aesthetics, I think the client wants you to make something look good. You also have the designer as an activist, where they're trying to communicate something that they feel really strongly about. And then we did a project where we looked at the voting system, in Ireland, coming up to the referendum, which was very topical. And we said to the student body, 'what would you do to improve this?' And they went through a what we called a usercentred design thinking process, because that was perfect for that context. Where it isn't perfect for designing a book cover. You're not going to have a user centred design approach then. But you would have if it was a service design...it always depends on the context. You've a graphic designer, you've an industrial designer, you've a service designer, you've a UX designer...there's so many different roles in design. It always depends on what the context of the problem is. So in a voting process where you had to look at the user to find out what the user wanted and needed then it's perfect. But a book cover, it is you that is designing for a client or a brief, where the user doesn't come into it. The client comes in and says yes or no. There isn't a user as such in that process.

However, some other participants argued a different perspective.

A word that helps me make sense of it is 'experience' and I would argue that whether you're doing a book cover or whether you're doing a voting process, there's still a fair bit of experience there and our goal as a designer, be it professionally trained or through professional experience is to be able to listen to those emotional responses. And then where I think where design thinking really connects there, it's the rest of your constituents, be they or stakeholders or team mates, to start to think about experience more deeply and give you the space as a designer to be able to practice your craft and be able to deliver that great experience.

The best way to sell design and/or design thinking within an organisation is not to talk about design. It's to talk about the outcome which typically is the experience we experience.

\subsubsection{When does design thinking not work?}

Some participants flipped this question and gave examples of real life experiences where they believed design thinking was not used, but should have been used and tested to produce a better outcome. 
Every time I arrive at Frankfurt airport, I feel stupid because I don't find the way. Basically, the system of how they arranged the airport, as I don't think there was anyone thinking about it...but basically the placement of things in context of walking around. So I don't think there was design thinking actually practiced and seeing how it functions. Also buying a ticket in the transportation system, it is extremely difficult for a nonGerman speaker, so I don't think these things were tested.

Overall it was felt that design thinking did not work when it is applied as a rigid and overprescribed process that can be applied to all projects.

When it's viewed as a rigid process and/or an absolute solution for all problems. Arguably there are no absolutes.

It depends on the context. It could be too limited, patronising and creative oriented for certain kinds of complex local problems and some stakeholders.

When a challenge needs a quick answer/fix and the context is mighty regulated/structured.

When it is seen as profit making fast solution.

Design thinking doesn't work when a company or (person) seeks immediate profit. Design thinking needs more time. Design thinking needs more money and time. The CEO doesn't want to pay for that.

Design thinking was also believed not to work when there was a lack of skill and knowledge amongst those practicing it, when there was poor collaboration amongst the participants and when it is imposed on unwilling players.

Design thinking doesn't work if the person must work with a project without the necessary practical experience about the design project.

When subtle differences matter a lot. Lacking deep skills (experience) makes impossible to make certain decisions fast and effective.

It was also believed that design thinking did not necessarily work across cultural boundaries, with some final thoughts eluding to a change of phrase by dropping the word 'design' from design thinking.

When crossing cultures and bringing 'local' way of design thinking to a new context and expecting it to run on its own in a new locality where the whole context is lost in space.

I think we need to totally change our thinking, the word design should be evaporated, and put thinking... when are we going to start thinking as human beings. We have a thinking brain but where does the thinking happen and how is it executed...design thinking is just too much.

If we want to be the catalyst of positive change, in general, the 'design' should be dropped for this word...maybe design thinking should be called 'problem-finding' thinking or something like that. 


\subsection{The DRS2018 Discussion and the path forward}

The Peak design thinking Conversation was well attended by participants and harvested interesting objective debate. One of the clear messages that came out of the session was the agreement that we have a divided opinion on the use and scope of design thinking as a mindset and process. Some initial feedback from participants suggested the format could also have been focussed entirely on the poster propositions, as opposed to the question prompts, and this is something we may consider for future data gathering.

The subject of design thinking clearly provokes a range of polarising opinions, as the responses from the participants in this Conversation highlights. The conveners believe that there is a great scope to further pursue a number of the points raised within this Conversation over a broader audience of contributors and across different territories, to reveal any discernible consistencies in viewpoint, and also to develop opportunities where participants can further elaborate on experiences of design thinking to act as case studies in reviewing more systematically the impact of applying design thinking methodologies across a range of contexts.

The findings reveal a need for a framework that can better define both Design and design thinking, their scope, their differences how they can complement each other. This would then provide companies and educators a means of determining the skills sets and disciplines when creating solutions for problems or opportunities. 


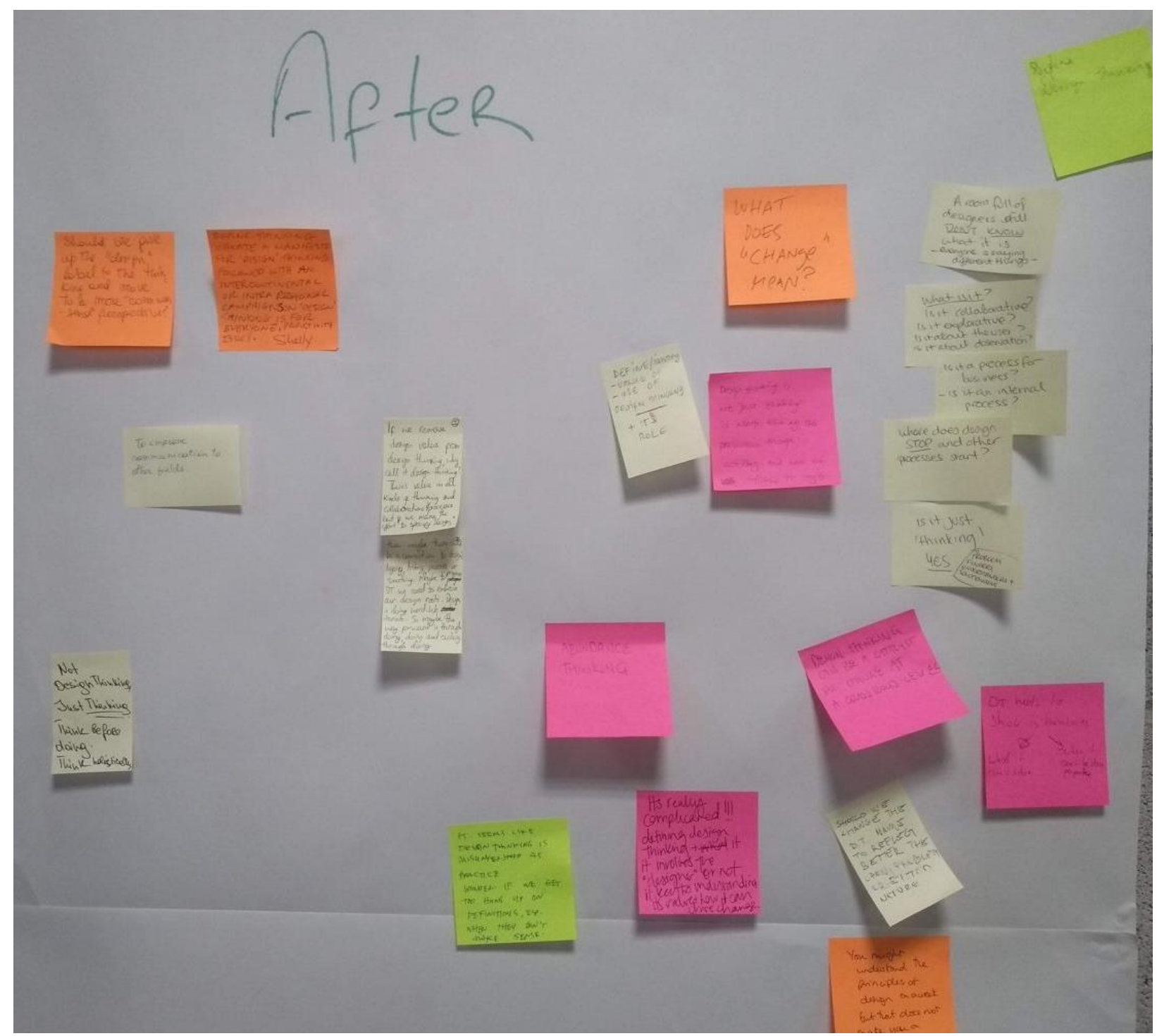

Figure 7 Final thoughts at end of session

\section{References}

Brown, T., 2009. Change by Design. 1st ed. s.l.:Harper.

Buchanan, R., 1992. Wicked Problems in Design Thinking. Design Issues, Volume 8.

Di Russo, S., 2016. Understanding the behaviour of design thinking in complex environments. s.I.:s.n.

Huffington Post, 2014. Live at Davos: 2014 Tim Brown. [Online]

Available at: Ideo CEO Tim Brown: 'Everyone Is A Designer'

[Accessed 2018].

Jones, J. \& Thornley, D., 1963. Conference on Design Methods. Oxford: Pergamon.

Kimbell, L., 2011. Rethinking Design Thinking: Part 1. Design and Culture, Volume 3.

Martin, R., 2009. The Design of Business. s.I.:Harvard Business Press.

Norman, D., 2010. Core 77. [Online]

Available at: http://www.core77.com/posts/16790/design-thinking-a-useful-myth-16790

[Accessed 9 Feb 2018].

Norman, D., 2013. Core 77. [Online]

Available at: http://www.core77.com/posts/24579/Rethinking-Design-Thinking

[Accessed 9 Feb 2018].

Nussbaum, B., 2011. Design Thinking Is A Failed Experiment. So what's next?. [Online] Available at: https://www.fastcodesign.com/1663558/design-thinking-is-a-failed-experiment-so-whats-next_[Accessed 9 Feb 2018]. 
Rowe, P., 1987. Design Thinking.. Cambridge, MA: MIT Press..

Simon, H., 1969. The Sciences of the Artificial. Cambridge, MA: MIT Press.

Vinsel, L. (2017, 12 06). Design Thinking is Kind of Like Syphilis - It's Contagious and Rots Your Brains.

Retrieved from Medium: https://medium.com/@sts_news/design-thinking-is-kind-of-like-syphilis-itscontagious-and-rots-your-brains-842ed078af29

About the Authors:

Michelle Douglas is a senior design academic with global experience. Her research interests are in design ecosystems and practice and the value of design in geographic regional contexts. She lectures on design thinking, collaborative practice and experience design at Masters level.

Dr Louise Kiernan is a product design lecturer at the University of Limerick. She has sixteen years of industry experience as a senior design engineer and product designer. Her research interests include, team collaboration, design education and design for health.

Jon Spruce lectures in the design of objects and spaces, his research interests focus on exploring how design education may be developed through increased dialogue and understanding between academics, the design industry, users of design services and consumers of design

Dr Annmarie Ryan is a Lecturer in Business Marketing. Her research interests relate to interaction and relationships between business and the arts, and on lived experience of interdisciplinary working. Her work has been widely published in Marketing and management literature 